\title{
Continuous Galvanized Rebar at the Cusp of a Market Breakthrough
}

ISSN: 2639-0574

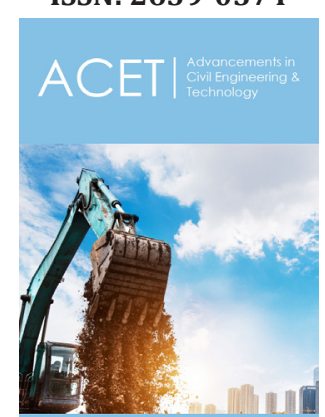

*Corresponding author: Mike Stroia, GalvaBar, 5101 Bird Creek Ave, Catoosa, USA

Submission: 毞 July 10, 2020

Published: 眥July 23, 2020

Volume 4 - Issue 3

How to cite this article: Daniel Liu, Mike Stroia. Continuous Galvanized Rebar at the Cusp of a Market Breakthrough. Adv Civil Eng Tech. 4(3). ACET.000586. 2020. DOI: $10.31031 /$ ACET.2020.04.000586

Copyright@ Mike Stroia, This article is distributed under the terms of the Creative Commons Attribution 4.0 International License, which permits unrestricted use and redistribution provided that the original author and source are credited.

\author{
Daniel Liu ${ }^{1}$ and Mike Stroia ${ }^{2 *}$ \\ ${ }^{1}$ Product Technology Centre, Teck Metals Ltd., Canada \\ ${ }^{2}$ GalvaBar, USA
}

\begin{abstract}
Ductile Continuous Galvanized Rebar is an innovative product which has recently become available in North America. Its excellent corrosion resistance renders it an ideal option for construction exposed to de-icing salts. The first successful application in bridge construction was completed in Iowa in 2018. The product also has applications in precast concrete components and where corrosion resistant reinforced concrete is used.
\end{abstract}

Keywords: Continuous galvanized rebar; Corrosion resistant rebar; Corrosion protection; Road and bridge construction; Concrete reinforcement.

\section{Introduction}

Conventional Hot-Dip Galvanized (HDG) rebar (in accordance with ASTM A767 specification) has been used in construction for over a century. One of its legacies is the Sydney Opera House at the waterfront of Sydney Cove. The HDG rebar has protected this architectural marvel from an aggressive marine environment for nearly half a century. Road and bridge inspections also revealed that after decades of service, the HDG rebar was still in excellent condition, even in concretes that were saturated with chloride. However, the HDG coating is largely composed of brittle iron-zinc intermetallic compounds, which severely limit the formability of HDG rebar, and hence its convenient application in construction. This shortcoming has been overcome with the innovation of continuous galvanized rebar.

\section{Benefits of Continuous Galvanized Rebar}

Continuous Galvanized Rebar (CGR, in accordance with ASTM A1094 specification) is a product processed by GalvaBar since 2018. It inherits all the benefits of conventional HDG rebar, such as proven performance in corrosion protection, excellent abrasion resistance and strong bonding with concrete. However, it overcomes the weakness of HDG rebar - poor formability. HDG rebar cannot endure the bending process at the construction site or at the fabricators' shops. Its brittle iron-zinc intermetallic coating spalls when severely deformed or re-bent during installation. Conversely, CGR has a ductile pure zinc coating, hence it can be bent and deformed without any danger of coating failure, as demonstrated in Figure 1. Fabricators readily embrace CGR when assured that CGR is equivalent to HDG rebar in corrosion performance. Specifiers, such as DoTs (Department of Transportation), take a careful approach when ushering in a new product. However, there is a growing number of applications where CGR has been used. The completion of a bridge over the Buffalo Creek in Independence, Iowa, (Figure 2) in 2018 established the first case study of CGR in the important sector of road and bridge construction [1]. Of the over 611,000 bridges in the USA, 87,601 (14.3\%) of them used epoxy coated rebar (ECR, in accordance with ASTM A775 specification), and only 1,226 (0.2\%) used HDG rebar [2]. Roads and bridges built using ECR a few decades ago have gradually shown signs of failure. Time has proven that ECR is not as good a product as promised by its promoters. The biggest issue with ECR is that when the 
coating is compromised by either mechanical damage or production defects, such as pores and uncoated areas, accelerated corrosion occurs beneath the epoxy coating. When that happens, ECR can fail locally even faster than unprotected black rebar. Many jurisdictions, including Florida, Virginia, and Ontario (Canada), have banned the use of ECR in public projects. A replacement product is needed to fill the void left by ECR. CGR, with its ease of handling and competitive price, offers an excellent alternative product for road and bridge construction.

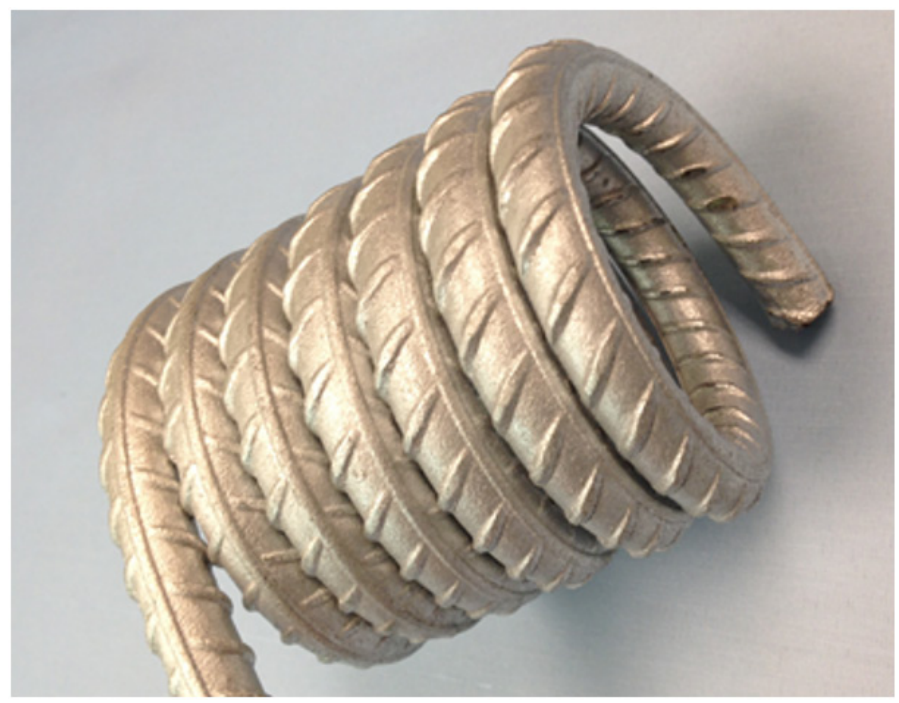

Figure 1: Continuous Galvanized Rebar exhibits excellent formability.
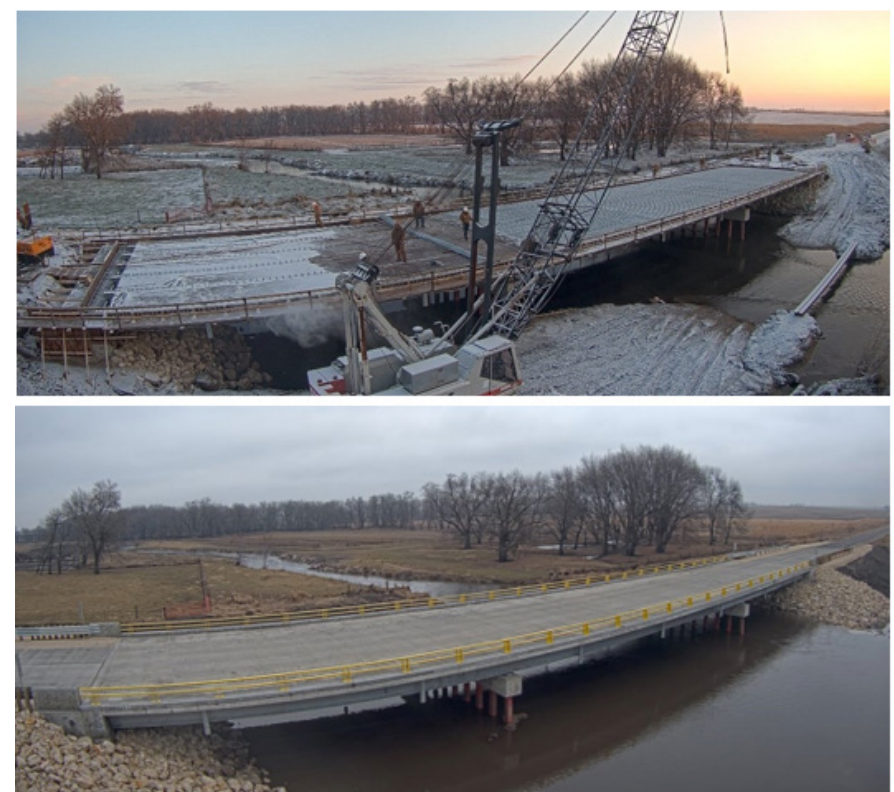

Figure 2: Buffalo Creek bridge built in Iowa in 2018 used over 100 tons of CGR for deck, abutments and parapets [1].

The physical appearance and quality of CGR bundles are more attractive than HDG counterparts. Processed on well guided conveyors, CGR maintains its straight form during the galvanizing process. The formation of brittle iron-zinc intermetallic layers in the galvanized coating is greatly suppressed due to the short dipping time in molten metal, and the addition of aluminum to the molten zinc galvanizing bath. As a result, the coating thickness is wellcontrolled, even on steels containing significant amounts of silicon. However, the bath aluminum content, though moderate at $0.2 \%$, is incompatible with the conventional flux used in the HDG process. The CGR process is enabled by Teck's proprietary aluminumcompatible G-flux (US Patent US7811389B2, granted Oct. 10, 2010). Coating thickness and appearance is aided in a final step where it wiped smooth using air knives (Figure 3). The CGR process also eliminates acid pickling and is therefore more friendly to the environment. The process is largely autonomous, thus substantially reducing the labor intensity of workers, while guaranteeing the consistency of product quality. This process was first used in the production of galvanized profile steels [3]. Production of other long products using this process in North America is being planned [4]. The overall production cost of CGR is slightly lower than that of HDG rebar, allowing CGR to compete favorably in the market. CGR could replace HDG rebar in many construction applications and gradually displace the large market share currently enjoyed by ECR.

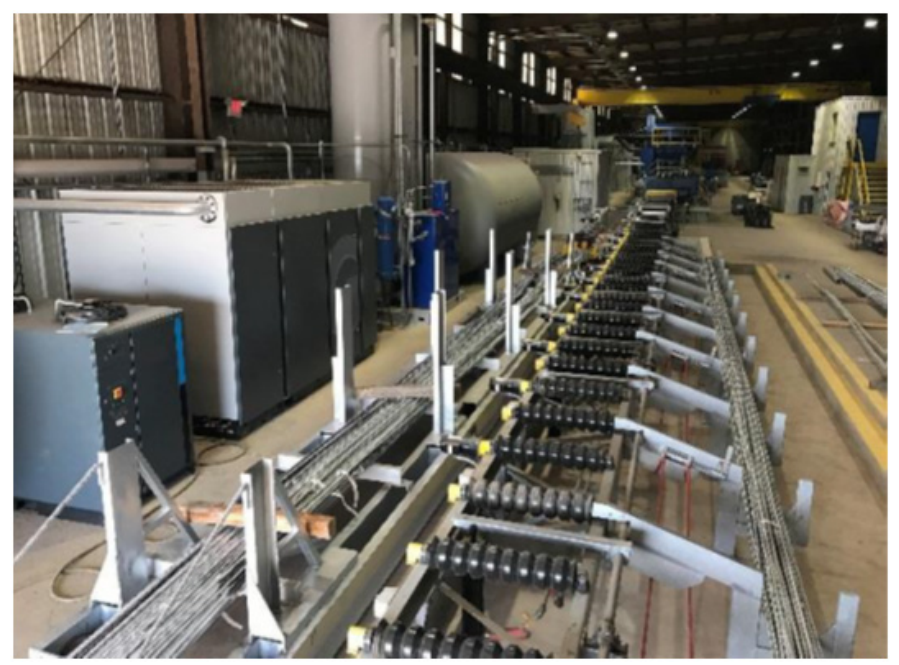

Figure 3: A straight bundle of CGR produced at the GalvaBar Catoosa plant [2].

Optionally, CGR can be coated with an epoxy topcoat to take full advantage of the synergistic effect of a barrier coating and a sacrificial coating. The duplex coated rebar (DCR, in accordance with ASTM A1055 specification) may offer well over 100 years of protection based on some accelerated test results, thus offering an economic alternative to costly stainless-steel rebar. Scientific studies on the performance of CGR and DCR in concrete are ongoing [5].

\section{Limitations of Continuous Galvanized Rebar}

Although current research and empirical evidence point to CGR providing equal or better protection than traditionally galvanized "batch" reinforcement, new products like CGR are slower to specify. American Concrete Institute (ACI) building codes adoption of CGR is pending, but ACI does recognize CGR in ASTM A1055 Zinc and 
Epoxy Dual-Coated Steel Reinforcing Bars. Additionally, current CGR processes allow size ranges from \#3 (.375) to \#11 (1.375) that leave out some larger size galvanized rebar.

\section{Summary}

Extending the life of reinforced concrete structures with galvanized reinforcement provides the lowest total cost to owners over the life of their structures. The durability of galvanized rebar coatings benefits contractors and placers in reduced downtime for costly repairs that ECR can lead to at the job site. Specifications ASTM A1094 or ASTM A767 are readily available in the marketplace throughout North America. Improvements in the formability of CGR allow for an inventory of corrosion resistant reinforcement that can be fabricated without special equipment.

\section{References}

1. AZZ Website (2019) GalvaBar ${ }^{\mathrm{TM}}$ helps expedite completion of bridge replacement project.

2. Stroia M (2018) Continuous galvanized rebar: Proven Protection-Innovative Process. National Bridge Preservation Partnership Conference (NBPPC), Orlando, Florida, USA, Presentation B3-1.

3. Harrison D, Liu D (2011) Corrosion resistance of continuous hot-dip Zn12Al coatings. Galvatech'11, Genoa, Italy, pp. 1-10.

4. Stroia M, Liu D (2020) A continuous galvanizing process for long steel products. AISTech 2020, Cleveland, Ohio, USA.

5. Cubides Y, Karayan I, Castaneda H (2020) Comprehensive corrosion performance study for materials used for reinforced concrete (RC) system/ elements. Research Report, Texas A\&M University, College Station, Texas, USA, pp. 1-22.

For possible submissions Click below: 